\title{
The Associations Among Symptoms, Quality of Life, and Gastric Emptying: An Unresolved Issue
}

\author{
Tae Hee Lee \\ Institute for Digestive Research, Soonchunhyang University Seoul Hospital, Seoul, Korea
}

\section{Article: Association between symptoms, quality of life, and gastric emptying in dyspeptic patients Wuestenberghs F, Juge M, Melchior C, Desprez C, Leroi AM, Gourcerol G (J Neurogastroenterol Motil 2019;25:534-543)}

Functional dyspepsia (FD) is a chronic disorder of gastroduodenal function that is characterized by one or more of the following symptoms: epigastric pain, epigastric burning, postprandial fullness, and early satiation in the absence of any organic disease that is likely to explain the symptoms. ${ }^{1}$ A recent meta-analysis indicated that the overall pooled prevalence of dyspepsia is $21 \%$ and varies among countries and according to the definition of dyspepsia. ${ }^{2}$

Patients with dyspepsia have reduced health related quality of life (HRQOL) because of their symptoms. ${ }^{1}$ HRQOL describes patients' perceived physical and mental health status. FD is not related to increased mortality. Therefore, HRQOL assessment is important to understand the impact of disease and treatments on patients.

Controversy exists as to whether delayed gastric emptying is related to specific symptoms or symptom severity (Table). A few studies indicated that gastric emptying may not be useful for stratifying patients with FD regardless of how the data were analyzed. ${ }^{3-6}$ However, postprandial fullness has been reported to be significantly related to impaired gastric emptying. ${ }^{7-12}$ Specifically, Stanghellini et $\mathrm{al}^{7}$ reported that female sex, relevant and severe postprandial fullness, and severe vomiting are independently associated with delayed gastric emptying of solids.

Controversy also exists over whether gastric emptying impacts on the HRQOL in patients with dyspepsia (Table). Talley et $\mathrm{al}^{13}$ reported that patients with dysmotility-like symptoms had significantly worse HRQOL than those with ulcer-like symptoms. In the population based cross-sectional endoscopic study applying the Rome III definition for FD, postprandial distress syndrome impair HRQOL in all short form-36 domain more than epigastric pain syndrome. ${ }^{14}$ These observations suggest the possibility that gastric emptying may have a significant impact on HRQOL in patients with FD.

In this issue of Journal of Neurogastroenterology and Motility, Wuestenberghs et $\mathrm{al}^{15}$ assessed association between symptoms and gastric emptying in 198 patients with dyspepsia. The main findings were that there was no association between symptoms, quality of life, and gastric emptying in their population. However, there was a significant association among symptoms, quality of life, and gastric emptying in their analysis using a different criteria (ie, $T_{1 / 2}=200$ minutes). That means that patients with severely delayed gastric emptying had worse symptoms and poorer quality of life. Given this finding, the authors questioned the traditional reference value of

Received: September 2, 2019 Revised: None Accepted: September 19, 2019

(.) This is an Open Access article distributed under the terms of the Creative Commons Attribution Non-Commercial License (http://creativecommons. org/licenses/by-nc/4.0) which permits unrestricted non-commercial use, distribution, and reproduction in any medium, provided the original work is properly cited.

*Correspondence: Tae Hee Lee, MD, PhD Institute for Digestive Research, Digestive Disease Center, Soonchunhyang University Seoul Hospital, 59, Daesagwan-ro, Yongsangu, Seoul 140-743, Korea Tel: +82-2-710-3084, Fax: +82-2-709-9696, E-mail: iman0825@schmc.ac,kr 


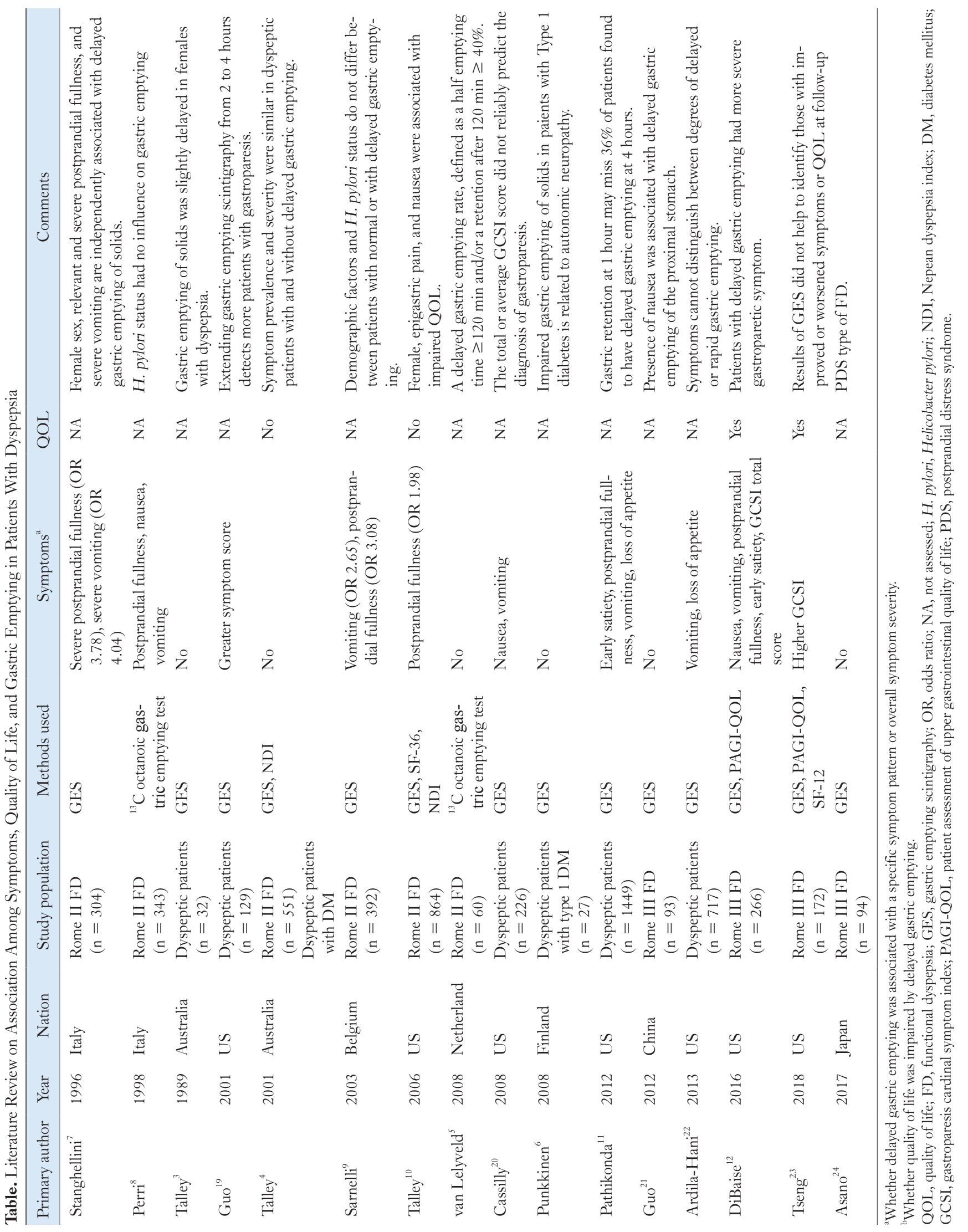




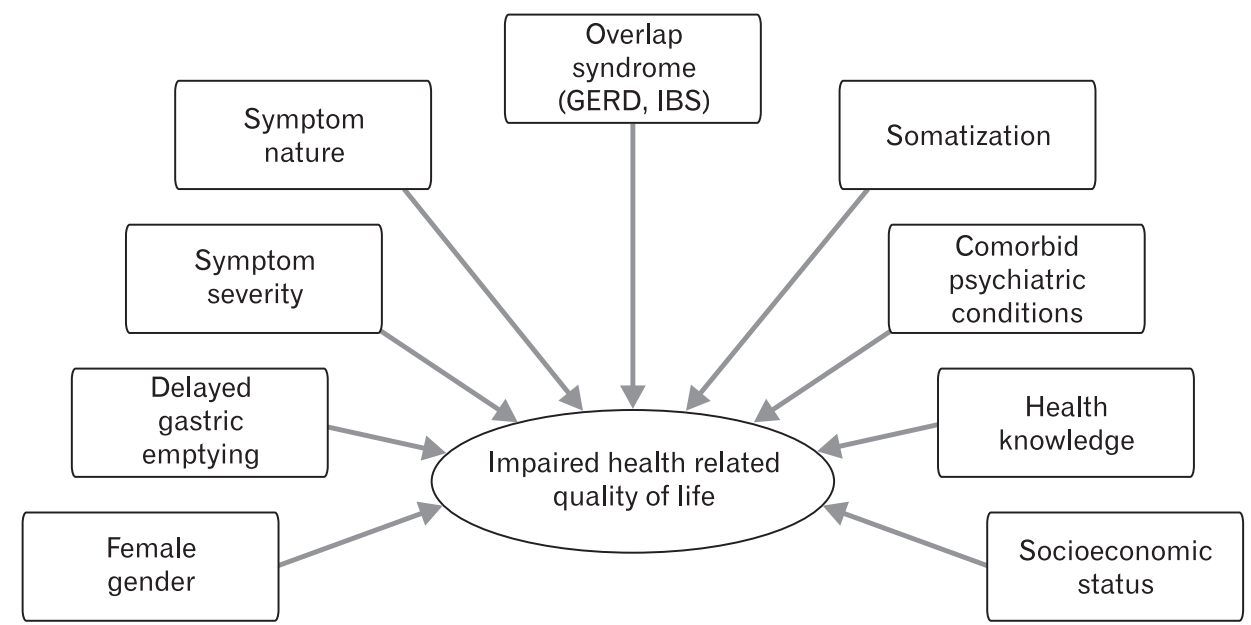

Figure. Putative factors impacting on the health related quality of life in patients with functional dyspepsia. GERD, gastroesophageal reflux disease; IBS, irritable bowel syndrome. delayed gastric emptying in the assessment of ${ }^{13} \mathrm{C}$ breath test using octanoic acid incorporated into a solid meal. Their study also highlights the need to assess normal values for this test. This breath test, which requiring standardization and validation, is an alternative to gastric emptying scintigraphy. ${ }^{16}$ The drawbacks of this gastric emptying breath test are that the reference range depends on the protocol and mathematical analysis method used. ${ }^{17}$ Dichotomous value (ie, normal versus abnormal) based on the threshold of 166 minutes in this study potentially undermines the diagnostic utility, and can be misleading. This analysis also erroneously implies that symptoms, quality of life, and gastric emptying were unrelated. Hence, it may be preferable to compare these metrics expressed on a continuous scale. The authors indicated that among the overall population, gastric emptying correlated with symptom severity assessed by total symptom score $(r=-0.215, P=0.002)$, quality of life assessed by the gastrointestinal quality of life index (GIQLI; $r=-0.227, P=$ $0.001)$, and anxiety and depression assessed by the hospital anxiety depression scale $(r=0.206, P=0.004)$.

Impaired HRQOL in patients with $\mathrm{FD}$ is mainly associated with symptom severity (ie, moderate to severe symptoms). ${ }^{18}$ Putative factors related to reduced HRQOL include gender, symptom nature (ie, FD subtype), overlap with gastroesophageal reflux disease (GERD) or irritable bowel syndrome (IBS), somatization, comorbid psychiatric conditions such as anxiety and depression, health knowledge, and socioeconomic status (Figure). ${ }^{18}$ In particular, overlap conditions with IBS or GERD might be important to understand the impact on HRQOL. Specifically, a populationbased study applying the Rome III showed FD overlap both with IBS and GERD had a significant impact on bodily pain. ${ }^{14}$ In addition, Wuestenberghs et $\mathrm{al}^{15}$ reported that patients with IBS present poorer quality of life (GIQLI scores of 71.9 points compared to
83.6 without overlap with IBS, $P=0.002$ ). As mentioned above, these factors may be confounders that distort the association among gastric emptying, symptoms and HRQOL. Therefore, the unresolved issue require further large study which utilizes a validated gastric emptying test and minimizes the effects of these confounders during study design and statistical analysis.

Financial support: This work was supported by the Soonchunhyang University Research Fund.

Conflicts of interest: None.

\section{References}

1. Stanghellini V, Chan FK, Hasler WL, et al. Gastroduodenal disorders. Gastroenterology 2016;150:1380-1392.

2. Ford AC, Marwaha A, Sood R, Moayyedi P. Global prevalence of, and risk factors for, uninvestigated dyspepsia: a meta-analysis. Gut 2015;64:1049-1057.

3. Talley NJ, Shuter B, McCrudden G, Jones M, Hoschl R, Piper DW. Lack of association between gastric emptying of solids and symptoms in nonulcer dyspepsia. J Clin Gastroenterol 1989;11:625-630.

4. Talley NJ, Verlinden M, Jones M. Can symptoms discriminate among those with delayed or normal gastric emptying in dysmotility-like dyspepsia? Am J Gastroenterol 2001;96:1422-1428.

5. van Lelyveld N, Schipper M, Samsom M. Lack of relationship between chronic upper abdominal symptoms and gastric function in functional dyspepsia. Dig Dis Sci 2008;53:1223-1230.

6. Punkkinen J, Färkkilä M, Mätzke S, et al. Upper abdominal symptoms in patients with Type 1 diabetes: unrelated to impairment in gastric emptying caused by autonomic neuropathy. Diabet Med 2008;25:570-577.

7. Stanghellini V, Tosetti C, Paternico A, et al. Risk indicators of delayed gastric emptying of solids in patients with functional dyspepsia. Gastroen- 
terology 1996;110:1036-1042.

8. Perri F, Clemente R, Festa V, et al. Patterns of symptoms in functional dyspepsia: role of Helicobacter pylori infection and delayed gastric emptying. Am J Gastroenterol 1998;93:2082-2088.

9. Sarnelli G, Caenepeel P, Geypens B, Janssens J, Tack J. Symptoms associated with impaired gastric emptying of solids and liquids in functional dyspepsia. Am J Gastroenterol 2003;98:783-788.

10. Talley NJ, Locke GR 3rd, Lahr BD, et al. Functional dyspepsia, delayed gastric emptying, and impaired quality of life. Gut 2006;55:933-939.

11. Pathikonda M, Sachdeva P, Malhotra N, Fisher RS, Maurer AH, Parkman HP. Gastric emptying scintigraphy: is four hours necessary? J Clin Gastroenterol 2012;46:209-215.

12. DiBaise JK, Patel N, Noelting J, Dueck AC, Roarke M, Crowell MD. The relationship among gastroparetic symptoms, quality of life, and gastric emptying in patients referred for gastric emptying testing. Neurogastroenterol Motil 2016;28:234-242.

13. Talley NJ, Weaver AL, Zinsmeister AR. Impact of functional dyspepsia on quality of life. Dig Dis Sci 1995;40:584-589.

14. Aro P, Talley NJ, Agréus L, et al. Functional dyspepsia impairs quality of life in the adult population. Aliment Pharmacol Ther 2011;33:12151224.

15. Wuestenberghs F, Juge M, Melchior C, Desprez C, Leroi AM, Gourcerol G. Association between symptoms, quality of life, and gastric emptying in dyspeptic patients. J Neurogastroenterol Motil 2019;25:534543.

16. Camilleri M, Parkman HP, Shafi MA, Abell TL, Gerson L; American College of Gastroenterology. Clinical guideline: management of gastropa- resis. Am J Gastroenterol 2013;108:18-37.

17. Keller J, Bassotti G, Clarke J, et al. Expert consensus document: advances in the diagnosis and classification of gastric and intestinal motility disorders. Nat Rev Gastroenterol Hepatol 2018;15:291-308.

18. Hantoro IF, Syam AF, Mudjaddid E, Setiati S, Abdullah M. Factors associated with health-related quality of life in patients with functional dyspepsia. Health Qual Life Outcomes 2018;16:83.

19. Guo JP, Maurer AH, Fisher RS, Parkman HP. Extending gastric emptying scintigraphy from two to four hours detects more patients with gastroparesis. Digestive diseases and sciences 2001;46:24-29.

20. Cassilly DW, Wang YR, Friedenberg FK, Nelson DB, Maurer AH, Parkman HP. Symptoms of gastroparesis: use of the gastroparesis cardinal symptom index in symptomatic patients referred for gastric emptying scintigraphy. Digestion 2008;78:144-151.

21. Guo WJ, Yao SK, Zhang YL, Yan J, Yin LJ, Li HL. Relationship between symptoms and gastric emptying of solids in functional dyspepsia. J Int Med Res 2012;40:1725-1734.

22. Ardila-Hani A, Arabyan M, Waxman A, et al. Severity of dyspeptic symptoms correlates with delayed and early variables of gastric emptying. Dig Dis Sci 2013;58:478-487.

23. Tseng AS, Crowell MD, DiBaise JK. Clinical utility of gastric emptying scintigraphy: patient and physician perspectives. Neurogastroenterol Motil 2018;30:e13279.

24. Asano H, Tomita T, Nakamura K, et al. Prevalence of gastric motility disorders in patients with functional dyspepsia. J Neurogastroenterol Motil 2017;23:392-399. 